\title{
UDSALI JA ADSELE
}

\author{
EVAR SAAR
}

\begin{abstract}
Annotatsioon. Artiklis vaadeldakse üht Lõuna-Eesti kohanimepesa Udsali Utsali. See nimi on olnud kasutusel talupoja lisanimena, läinud sajanditel laiemalt kui tänapäeva kohanimedes. Materjali esitamise käigus juhitakse tähelepanu mõnele XVI sajandi mainingule, mis sisaldavad etnonüümi meenutavat lisanime *Udsalane ${ }^{1}$. Lisanime Udsali võrreldakse lisanimega $U d s u$, selle sõnavaralise vastega $u d s u$ 'udu, ebe, udusulg' ja vana karunimetusega *otś : ote. Põhjalikumalt keskendutakse kõrvutusele Kirde-Läti muinasmaakonna nimega Adsele $\sim$ Agzele. Pakutakse välja Adsele nime detailne läänemeresoome etümoloogia. Selle järgi on algupäraselt olnud tegemist ikkagi $a$-algulise nimega. Uuritakse võimalusi, kas $a$-algulisest kohanimest oleks võinud kujuneda $u$-alguline lisanimi. Kokkuvõtteks järjestatakse Udsali nime päritolu vähem usutavad ja tõepärasemad hüpoteesid.
\end{abstract}

Võtmesõnad: onomastika, lisanimed, etnonüümid, kohanimed, etümoloogia, lõunaeesti keel, läti keel

\section{Lisanimeainestik}

Udsali- ja Utsali-nimelisi kohti leidub tänapäeval Võrumaal ja Tartumaal. Haanjas on neid kohti kõige rohkem. Seal ilmusid sellised lisanimed-talunimed dokumentidesse XVII sajandil, Puurmanis XVIII sajandil (EKNR: Ihatsi, Udsali, Utsali). Varaseimad levikupiirkonnad on Lääne-Võrumaa ja Tarvastu.

Oleg Roslavlev publitseeris 1970. aastatel mahuka sarja Poola ametnike koostatud dokumente Lõuna-Eestist pealkirja „Polnische Akten“ all. Publikatsiooni I ja II osa sisaldavad materjale Tartumaalt, IV osa Viljandi- ja Pärnumaalt. Ilmumata jäid III ja V osa, mida koostaja ise on IV osa eessõnas maininud (PA IV: 3). Talupoegade nimed nendes mahukates köidetes pole tänapäevani põhjalikku käsitlemist leidnud.

\footnotetext{
1 Tärn * nimekuju või sõna ees märgib oletuslikku vormi.
} 
Siinses artiklis puudutatakse niisiis üht silmatorkavat lisanimede rühma. Võimaluse korral on lisatud näiteid samade lisanimede kasutamise kohta XVII sajandi revisjonides.

1585 Sangaste mõisa Karula khk osas Arho külas Sten Oczlan (PA I: 170) 1586 samas kohas Szym Odzalan ja Mik Odzalan (PA II: 324)

1588 samas kohas Czym Odzalan (PA I: 237)

1592 samas kohas Czym Odzal (PA II: 451)

1601 samas kohas Utzula Zimen (Rev 1601: 35)

Kadunud nimega Arho küla paiknes kusagil Korijärve ja Karula kirikumõisa vahel (mitte segi ajada Vana-Antsla mõisa Aruküläga lõuna pool).

1588 Vana-Antsla mõisa *Sääslä külas (Saslakula) Mius Uczal z Simonem

Markuspoikiem 'koos Siimon Markuspojaga' (PA I: 256)

1592 samas kohas kubjas Simon Vdzela (PA II: 446)

1601 Vana-Antsla Errekull'i külas Utzell Simon (Rev 1601: 60)

*Sääslä külast on saanud Kuldre ja Kõlbi küla, Errekull võiks oletamisi olla Oeküla lääneosa Ärnu jõe ehk teise nimega Õru ääres.

Pärast XVII sajandi alguse suuri vapustusi ilmus nimi Vdzal Hin välja 1638. aastal lähikonnas Vaabina mõisas (Rev 1638: 53). Nime kandjast sai alguse tänane Sõmerpalu valla Udsali küla.

Tarvastu kihelkonnas Riuma külas elas 1583. aastal pobul Uczely Piep. 1587 oli Uczali Piep registris kui uus taluperemees (PA IV: 146, 243).

Huvipakkuv, kuid Udsali nimedega seostamise jaoks pisut kahtlane on 1583. aastal Tarvastu külas esinenud Uczenik Aliewerko, 1586 ja 1587 Uczanik Aliewerko (PA IV: 142, 219, 241). Ristinimi Aliewerko on haruldane ja tundmatu (<Oliver?). Udsalitega samatähendusliku lisanime realiseerumine nik-tuletisena oleks siiski mõeldav.

1638 elas Puhja kihelkonna Palupõhja külas Vdzal Maddi auszm Karckschen, bey Pohlen Zeiten herkommen 'Karksist, Poola ajal siia tulnud' (Rev 1638: 120). Ilmselt oligi tema see, kelle järglased Pedja jõge mööda üles minnes tekitasid Puurmani valla Utsali küla.

Haanja Uthsahla'd ilmusid XVII sajandi teise poole dokumentidesse mitmes talus korraga, mille tõttu ei tahaks selle nime kandjaid mõne Vana-Antsla või Karula siirdlase järeltulijateks pidada. Kokku võiks nime teadaoleva ilmumise kohti olla viis: Karksi, Tarvastu, Karula, Vana-Antsla ja Haanja. 
Poola-aegsetest Karulas esinevatest mainingutest tuleb välja, et see, keda nii on kutsutud, on saadud kutsuda ka odsalaseks $\sim$ udsalaseks ${ }^{2}$. Erinevalt Eesti kohanimeraamatus pakutud ülemsaksa või juudi laennime seletustest (EKNR: Udsali) olen nüüd seda meelt, et Udsali nime aluseks on pigem etnonüüm, hõimunimetus. Võib-olla peitub selles ka kohanimi *Udsala $\sim$ *Utsala? Lisanimeks ja hiljem talunimeks-külanimeks vormus kõikjal kollektiivne nimetus, mitmuse tunnusega nominatiiv Udsaliq Utsaliq, millest pärast kõrisulghääliku kadumist jäi alles genitiivseid kohanimesid meenutav kuju (vrd Pall 1997: 13-18). Teisest vaatenurgast võib seda nimekuju võtta kui lätipärast, läti mitmusliku li-lõpulise nime laenatud kuju. Dokumentides leidub mitmel korral ka a-lõpulist Utsalakuju: Haanjas 1684 Uthsahla, Puurmanis 1770 Utsala (EKNR: Udsali, Utsali). 1601. aasta Karula vorm Utzula meenutab allpool mainitud Udsu-lisanimesid.

\section{2. $u$ ja $o$ varieerumine, sõnavaralised võrdlused}

Esimeste Karulas esinenud mainingute nimealguse $o$ võib olla poola kirjaviisist tingitud. Selles positsioonis on $t s$-ühendi või lõunaeesti tugeva afrikaadi ees ajalooline $o$ hästi säilinud, nt $o t s a$-sõnaga algavates kohanimedes. Leidub isegi näide, kus tugeva afrikaadi ees on $u$ muutunud $o$-ks: Urvaste talunime Otśu on juba 1805 kirjutatud Oitso, aga veel varem, 1762 on seda Härjakurgu talust eraldunud talu kirja pandud kujul Härjakurgo (Hutso) (EAA.567.2.568: 3, L2p; EAA.1270.1.264: 177, L178). Kombinatsioonis, kus lõunaeesti nõrga afrikaadi ees on esisilbi lühike labiaalvokaal, leidub rohkem $u$-lisi, vähem $o$-lisi nimesid, nt Mudsina järv (Kan), talunimed Ludsa (Urv), Mudśo (Räp), aga ka Kodso (Rõu). Ei ole teada otseseid näiteid, kus algupäraselt $o$-line sõna oleks ühendi $-d s$ - mõjul $u$-liseks muutunud.

$u d s$-näiteks on mitmed Lõuna-Eesti lisanimed-talunimed $U d s u$ (mida on vahel kirjutatud Utsu $\sim$ Utso), perekonnanimed Udso, Udsu ja Utso. 1588 on *Sääslä külas peale nime Mius Uczal'i kirja pandud ka Udzo

2 Võrdluseks olgu samast Sangaste mõisa talupoegade loendist toodud nimekujud Mik ja Jurgi Sarlan 'saarlane' ja Wichtlan Toc (Vihtla lisanimest moodustatud lanelisanimi?) (PA I: 238). Muid lAne-nimede kujusid: Piotr Latlen, Piotr Lathlen, Toc Sarlan, eesti vokaallõpp ilmneb poola keele käändelistes vormides: Kierpsi Toc $z$ Vendalanem, Jurgi z Tatarlanem (PA I: 93, 228, 229, 250, 266). 
Mick. Ahjal on poola kirjutaja üles märkinud Jak Uczu (PA I: 256, 263). Vanim selle nimepesa teadaolev näide on $i$-lõpuline (?) talunimi või lisanimi $V d s y$ ( $V d s y$ Lemmitt) Taageperast Helmest XV sajandist (Johansen 1938: 54). Tänapäeval leidub sealgi $U d s u$-kohanimesid. Mulgimaa ja vana Võrumaa $U d s u$-nimesid võiks küll $U d s a l i$-nimedega seostada. Sõna udsu tänapäevane tähendus on 'udu, ebe, udusulg'. Selline tähendus sobib iseenesest hästi inimest iseloomustavaks lisanimeks. Udsali-nimedega lähedane on verb udsalõma '(udsu kombel) hõljuma' (VES: udsalõma). Puhtalt apellatiivne $u d s u$ on üks $U d s a l i$-lisanime võimalikest alustest.

Läänemeresoome ja mordva keelte vana karunimetus *okti okte(vrd kuramaaliivi okš, salatsiliivi oks, soome idamurrete ohto, ersa ovto, ofto, mokša ofta 'karu') (Oksanen 2007: 89; SLW: 137) peaks lõunaeesti keeles olema olnud reeglipäraselt *otś, genitiiv *ote(n) (vrd ütś : üte, vrd Otepää Otõmpää, vrd Alvre 1985: 96). Rahvapärane ott on selle lihtsustus, usutavasti laenulise isikunime Otto $>$ Ott mõjul. *Otś-sõnast moodustatud inimesenimetus *otślanõ haakuks ehk samuti mõne $U d s a l i-$ nimede varasema maininguga, nt Oczlan'iga. Ehk on seegi mõeldav, et osa $U d s u$-nimedest, eriti need, mille kirjapilt on Utso (vrd ka Urvaste talunime kuju Hutso), seostuvad hoopis vana karunimetusega? o- ja $u$-lõpulisena võiks see olla olnud isikunimi, karu tähendava sõna $o i$-deminutiiv.

\section{Adsele ja sellesarnased kohanimed}

Udsali ühendamist Kirde-Läti Adsele muinasmaakonna nimega takistab algushääliku sobimatus. Adsele tähtsus iseendast on esile tõusnud Heiki Valgu ja Silvia Laulu detailselt kirjeldatud arheoloogilise kultuuriga muinasaja lõpul ja keskajal. Seda kultuuri ei saa samastada ei latgalitega Ida-Lätis ega ugalastega Lõuna-Tartumaal ja Võrumaal. XIII-XVI sajandi ja ehk ka varasemat Adsele maarahvast tuleb pidada omaette etnoseks,

3 Soome idamurrete ohto on oi-tuletis: *okti $>*$ okte- $>$ oht- $(* k t>h t /$ / $($ mitte $i))$ $>+$ oi > ohtoi > ohto (Oksanen 2007: 92). Soome kirjakeele otso 'karu' puhul on keeleajaloolaste põhiseisukohaks, et see on algupäraselt $h t$-lise sõna rahvaetümoloogiline edasiarendus. Varased soome kirjakeele kujundajad arvasid, et nii nagu murretes on vihta 'vitsa [vits]', tuleb murrete ohto normida kujule * otso (Hakulinen 1979: 56). Siiski on otso tähenduses 'leveäotsainen [laialaubaline]' esinenud Soomes ka rahvakeelse sõnana (Oksanen 2007: 91). Võrdluses soome keelega tuleb tähele panna, et lõunaeesti häälikumuutused annavad reeglipäraselt *okti $>$ *otś $(>$ ott $)$. 
mis on tekkinud põlise läänemeresoome ja alates rahvaste rännu ajast sisse tunginud balti elanikkonna segunemisel (Valk, Laul 2014: 180-187).

Linnuse nime Adsele $\sim$ Adsel on kirja pandud peamiselt saksa keeles. Poolakeelses tekstis leidub ka Handzel zamek (PA II: 480). Läti keeles on Koivaliin ainult Gaujiena. Kuid Läti kohanimeraamatus leiduvad Valmiera kandi Kauguri valla talunimi Adzalis ja sellest sõltumatult mäenimi Adzalkalns, Lääne-Kuramaa Aizpute ümbruse mitmed talunimed ning mõisa nimi Adzel̦i, Adzel̦umuiza talu Rundāles, Ruhja kandi talunimi Adzelvietis jt. Koiva lisajõe Miegupe haru nimi Adzele on saanud nime Kauguri valla talunimest. Kazimieras Būga on neid nimesid pidanud läänemeresoomelikeks. Jānis Endzelīns on selles kahelnud, kuna Adzel-nimede leviku põhiala on üsna lõunas, Lääne-Kuramaal. (Lvv I: 5). Siiski, see piirkond Kuldīgast lõuna pool oli veel vähemalt 1355-1362 osaliselt liivi ja osaliselt balti hõimude rahvastikuga, kui kristluse-eelsete isikunimede järgi otsustada (Bauer 1933: 145-154). Antons Breidaks ühendas Adsele nime Karjala ja Ingerimaa kohanimedega Akkala, rekonstrueerides nimekuju * Akala. Breidaksi etümoloogia keskendub palataliseerimata ja tagavokaalses ümbruses $k$ afrikaadiks muutumise võimalikkusele. (Breidaks 1997: 100-101) Kaija Mallat peab Soome Akkala-nimesid saaduks isikunimest Akkainen Akkoinen (SPK: 19).

Vanavene kroonikate teateid sõjaretkedest tšuudide vastu на Очелу (Otšelasse) 1111. ja 1179/80. aastal (Valk, Laul 2014: 185) on vähemalt alates XIX sajandist peetud seotuks Adsele'ga. Diskussiooni, kas nimesid Очела, на Очелу võib samastada Adsele'ga, algatas Enn Tarvel (1975). Tarveli kahtluste keskmes oli kroonika sõnastus, et rünnatavad tšuudid põgenesid къ морю 'mere äärde, mere poole' (1975: 550). Tarvel ei soovitanud ka ühtegi teist kohta, kuid pakkus võrdluseks välja XIII sajandi Virumaa kohanimesid, Lüganuse vana nime Askaelae (puudus on see, et $s k$-d ei oleks asendatud vene keeles $\check{c}$-ga) ja häälikuliselt sobivama Atsalama (XIII sajandil Akimal), mida taas pole põhjust pidada suuremale piirkonnale nime andnud oluliseks keskuseks (Tarvel 1975: 552). Heiki Valk on esitanud lisaväiteid Adsele ja Otšela samastamise poolt, tugevdades niiviisi seisukohta, mida ajaloolased ka enne Tarveli artiklit üldiselt toetasid. (Valk 2009: 150, 153; Valk, Laul 2014: 185) 


\section{Adsele etümoloogia}

Seletuse, et kohanimi Atzele tuleb läänemeresoome sõnast, mis on liivi keeles $a d^{\prime} a$ ja mis tähendab 'kallast', pakkusid teadaolevalt esimest korda välja Krišjān Ancītis ja Aleksandr Jansons (1967: 303). Keeleliselt õigesti tabatud etümoloogia puuduseks on algupärase koha samastamine Gaujiena ehk Koivaliina'ga (sks Adsel), nii et nimi tähendaks asulat Koiva jõe kaldal, kaldaäärset asulat (Ancītis, Jansons 1967: 303). Adsele esimeses täiesti kindlas 1224. aastast pärinevas mainingus on siiski juttu maast nimega Agzele (terra, quae Agzele dicitur) (LUB I, nr LXX).

Adsele $\sim$ Agzele esikomponent täpsemalt on germaani laensõna läänemeresoome keeltes *akja - salatsiliivi $a d^{\prime} a \sim a d j a \sim a d^{\prime} \sim a g^{\prime}$ 'Rand, Ufer, Gegend [äär, kallas, maa-ala]', kuramaaliivi aigā 'äär', eesti murrete $a i$ 'Kante, Borte [riideeseme kant, serv]', soome aaja 'groß, weit [suur, lai]'. Vrd varase germaani algkeele *agjā (SLW: 41; SSA: aaja). Sõna esineb Liivi lahte suubuva Aǵe jõe nimes, mida on ladina ja saksa keeles kirjutatud Adya, Adia ja Adje, salatsiliivi keeles 1665 Ayia (SLW: 43). Aǵe nimi võib olla motiveeritud jõe kujunemisest Metsepole ja Koiva liivlaste piiriks (Pajusalu, Winkler 2011: 180). $a$-le järgneva klusiili palatalisatsioon, metateetiline palatalisatsioon, poolvokaalistumine ja kadumine toimivad selle sõna markeritena. Vana laensõnana kuulub aig $\bar{a} \sim a d^{\prime} a$ vaid kuramaaliivi ja salatsiliivi keele põhisõnavara hulka, mujal on see marginaalseks taandunud.

Adsele puhul püüab tähelepanu sarnane järelkomponent liivlaste tuntud linnusenimedes Henriku Liivimaa kroonikas: Sattesele (Livvu kalns Siguldas), Cubbesele (Ķizbele) ja küla Vitisele (Krimulda lähedal). Võib-olla liitub nimetüübiga ka liivlaste küla Cogelse (HLK: 68, 134, 224, 256, 257; Alvre 1985: 33). Nagu öeldud, pole Adsele mitte linnus ega küla, vaid maa, mille kõige olulisem keskus vahetult enne XIII sajandit oli linnus Alūksnes (Valk, Laul 2014: 184-185). Pihkva kroonikas esineb Alūksne esimest korda 1284 ja selle varased nimekujud on Ольста, Альстьь, Вольсть (Balode, Bušs 2015: 54-55). Koivaliina-Gaujiena linnus, saksa nimega Adsel(e), on rajatud XIII sajandil Agzele maa läänepoolsesse ossa Koiva jõele; maa nimi ei ole tekkinud selle linnuse kohas.

Suurte territooriumite nimed on tihti kujunenud linnusekohtade, nn võtmekohtade nimedest, need aga omakorda väikeste looduskohtade nimedest või isikunimedest. Adsele $\sim$ Agzele juhtumis näib olevat tegemist 
vastupidise ilminguga: linnus on nimetatud omaaegses keeles olemas olnud territooriumi nimega.

Ajaloolise Adsele piirkonna elanike omanimetusena on tänapäevalgi kasutusel malēnieši läti sõnast mala 'äär'. Näib, et (läänemeresoomlaste?) maa ääreala tähendav nimetus on olnud ka Adsele maarahva omanimetuse osaks ja läänemeresoome keele vahetudes läti keeleks on omanimetus tõlgitud.

Äärt tähendava esikomponendi tõlgenduse korral on $a$ järel olnud tegemist palataliseeritud $d$-ga, mis omakorda on suhteliselt lähedane palataliseeritud $g$-le, vrd salatsiliivi jog $a d^{\prime}$ 'Ufer des Baches [jõeäär]' ja märn ag' 'Strand [mereäär]', aǵnika 'gerandet, am Rande befindlich, Uferbewohner [ääristatud, serval leiduv, rannaelanik]', samuti ad'ama 'Rand, Ufer [äär, kallas]' (SLW: 41). Võrdluses XVIII-XIX sajandi salatsiliivi keelega võiks nime tõlgendada $* a d+$ sele $\sim a g+z e l e$. Siiski tekib siin kahtlus, et XIII sajandi Liivimaa liivi keel (mille kaudu sakslased seda nime tundma õppisid) peaks olema tunduvalt vähem kulunud ja lõpukadu ei tohiks veel olla.

Eeldades, et $a d^{\prime} a \sim a d^{\prime}$ varieerumisele XIX sajandi Salatsis eelnes XIII sajandil lõppvokaali säilimise periood, jääb mulje, et äärt tähistav sõna on vanades nimekujudes esindatud elemendina adse-, agze-, oye- (осеe-).

Kui tõmmata kõrvutusse kaasa Tarveli poolt Otšela puhul mainitud Virumaa külanimi Atsalama, siis ilmneb, et selline tõlgendus oleks vastuoluline. Juba Lauri Kettunen (1955: 69) pakkus, et Atsalama nime esiosas sisaldub seesama äärt, ääremaad tähendav sõna *akja. Nimeandmismotiiviks sobib külarühma asukoht soode vahel, Virumaa tiheda asustusega piirkonna serval. Eri kirjapilte: u 1241 Akimal, 1539 Achymal, 1655 Atzelama (EKNR: Atsalama). Siin saab näha palataliseeritud $* k^{\prime}$-st afrikaadi, praeguse eesti $t s$-ühendi kujunemist. Kettunen oli selle muutuse suhtes tähelepanelik ja seostas seda vadja keelega, kus eesvokaalide ees on toimunud muutus $k>t \check{s}$, Atsalama korral oleks see *aki- $>* a t s ̌ i-$, aga eestipärase substitutsiooniga atsi- (Kettunen 1955: 69). Kas vadjapärasus või mitte, Atsalama nime kirjapildid näitavad seda muutust üsna hästi. Ilmekas on siin baltisaksa kirjalik traditsioon, mis teatavasti hoidis vahel kinni arhailistest, keskajal omandatud nimekujudest: 1796 Aggemal oder Atzlema (EKNR: Atsalama).

Kõrvutades Atsalama ja Adsele XIII sajandi kirjapilte Akimal ja Agzele, süveneb seisukoht, et äärt tähendav sõna on siin pigem $a g$-. Järgnev 
-z- kuulub juba teise nimeosa algusse. Vene Очела (ос̌еla) aluseks olnud nime võib analüüsida kas * $a d^{\prime}+$ sela või * $a g^{\prime}+$ sela, nii ühendi $-d$ 's- kui ka ühendi -ǵs-puhul on selle asendamine $c$-ga ootuspärane. Ent kui nimes oleks juba XII-XIII sajandil olnud afrikaadiks muutunud klusiil - *aća $+l a$ - pidanuks saksa keeles tekkima teistsugune kirjapilt. Vadjapäraseks peetav afrikaadistumine mitu sajandit varem, kui see toimus Atsalama nimes, ning salatsiliivi keele naabruses, kus säilis algupärane $k^{\prime}-$ seda on raske põhjendada.

Sõna *akja lõppvokaali puudumist XII-XIII sajandil on lihtsam seletada. Nimemoodustuses esineb vokaali väljajättu ka sellistes läänemeresoome keeltes, kus lõpukadu pole üldse toimunud (nn Rautjärvitüüpi kohanimed). Selline sõnamoodustus võib ulatuda esimesse aastatuhandesse, sellel pole otsest seost põhjaeesti, lõunaeesti ega liivi üldise lõpukao arenemisega. Adsele kokkukuuluvus muude sele-nimedega näib ka tüpoloogiliselt usutavam.

Järelkomponent -sele liivipäraste kohanimede markerina on uurijatel kaua silme ees seisnud. Enamasti on tähenduseks pakutud 'selja'. (Alvre 1985: 33) Selle kohta, kuidas Liivimaa liivi keeles sele-nimede järelkomponendi vokaale tegelikult hääldati, pole palju teada. Nii ladina kui ka keskalamsaksa tekstide kirjutamisel avaldas mõju keskalamsaksa keel, milles järgsilpide vokaalid redutseerusid. Laennimedes neid ka kirjutati eelistatult $e$-ga, olenemata kohaliku keele hääldusest. Kui Adsele kuulub sele-nimede sarja, on vene kroonikate на Очелу $(<$ Очела) heaks näiteks, et need nimed on ikkagi lõppenud -lA-ga.

Paul Alvre ei pooldanud -sele ühendamist liivi sõnaga sālga 'selg', mis iseenesest oleks ehk linnusenimede puhul ootuspärane. Alvre vastuväiteks oli, et sā̄lga ei allu liivi keeles astmevaheldusele, kuid sele-nimedes ei nähtu kusagil $g$-ainest. Ta pakkus lahenduseks *nen-sõna omastavakuju -se, millele on liitunud la- lä-kohasufiks (Alvre 1985: 33). See annaks siis Adsele puhul *ad' + se + la, milles *ad'se võiks ühendada elanikega, veerepealsetega.

Siiski tuleb võimalikuks pidada, et Liivimaa liivi keeles tunti ka selga-sõna astmevahelduslikku varianti, midagi lõunaeesti võru sälg : säl(l)ä taolist. Salatsiliivi sälliš selliš ' auf dem Rücken, rücklings [seljas, turjal, selg ees]' (SLW: 174) näitab, et nõrga astme vormide esinemist ei saa välistada. 


\section{Sõna alguse $a$ ja $u$ ühitamise katseid}

Udsali ja Adsele kõrvutamise põhiline ajend on aastatel 1111 ja 1179 (1180) mainitud на Очелу. Kas sõnavaraliselt aluselt motiveeritud *Adsela saaks lõunaeesti keeles olla muutunud Udsala'ks? Kahjuks ei saa selle poolt esitada eriti tugevaid argumente. Läänemeresoome nime lühikese $a$ kirjutamine vanavene keeles $o$-ga on ootuspärane. Pole teada, kuidas seda hääldati. Kuigi tänapäeval on põhjavene murded läbivalt $o$-lise okanje aladeks, on Jalo Kalima läänemeresoome keelde vanavene laensõnu andnud keelt pidanud selliseks, mille $o$ oli olenemata rõhust akustiliselt lähedal läänemeresoome $a$-le (Kalima 1952: 31). Vanavene laensõnadele tüüpilist vastavust (vanavene $o$ - läänemeresoome $a$ ) silmas pidades ei saa isegi väita, et Очела kirjutanud kaasaegsed oleksid nime alguses labiaalvokaali $o$ hääldanud. Ka vene keelde võetud läänemeresoome laensõnades on selline häälikusuhe näha: лопарь 'laplane', лойва 'laev'.

$a$ labialiseerumise $(a>o)$ kohta lõunaeesti keeles on näiteid Leivu murrakust, nt pandma $>$ pondma 'panema'. Seal esineb seda vaid pearõhulises silbis ja labiaalse konsonandi naabruses (EM IX: 15), mida saab pidada tugevaks läti (latgalipärase läti keele) mõjuks. Tänapäeva latgali keeles ja läti malēnieši murdes on küllalt tavaline lühikese $a$ muutumine $o$-ks, see on palju laiemalt levinud kui üksnes labiaalsete konsonantide naabruses. Läti pikale $a$-le vastab latgali keeles alati uo (Leikuma 2003: 4). Ka kohanimede hulgas leidub piisavalt näiteid, eeskätt esineb $o$ muidugi labiaalsete konsonantide naabruses: Balvi-Bolvi, Madona-Moduona, samuti sufiksilaadsetes nimeosades: Kārsava - Kuorsova, Krāslava Kruoslova, kuid sageli ka mujal: Alūksne - Oluksne, Lazda-Lozda, Vanda - Vonda. Süstemaatilise vastavuse eeskujul on Gerhard Hoppe perekonnanimest saadud mõisanimi Ope $\sim O p a$, ametliku kohanimena kirjakeelsel kujul Ape (Balode, Bušs 2015). Nii nagu lazda 'sarapuu' on latgalipäraselt lozda, võib vähemalt teoorias kujutleda ka Lääne-Läti kohanimede Adzalis ja Adzel̦i Ida-Läti vasteid *odzalis ja *odzel̦i.

Teine võimalus Adsele ja Udsali vahel seost näha on ekspressiivse varieerumise põhine tekkemehhanism. Etnonüümid kuuluvad selliste sõnade hulka, mille kasutamisega võib kaasneda tundelaeng. Vesa Jarva on esitanud suure hulga varasemate uurijate näiteid ja väitnud nende põhjal, et ekspressiivsetes sõnapesades esineb kahtluseta kokku kuuluvaid variante, mille puhul ei saa rääkida samast sõnatüvest, kuid mille tekkimise alguspunktiks võib olla ikkagi üks kindel sõna, sageli laensõna. 
Sõnapesa arendamine on toimunud juhusliku varieerumise teel (Jarva 2003: 22-28). Juhuslikul varieerumisel on oluline, et keelekasutajad tunnevad ära samatähenduslikke ekspressiivsõna variante. Sageli esineb ilmekaid näiteid, kus sõna konsonandistruktuur jääb paika ja vahetatakse vokaale ${ }^{4}$ (Jarva 2003: 79-84).

Varieerumise *adsela(ne) *udsala(ne) mõjutajaks võis olla teine etnonüüm. Oletan, et sellist rolli võis mängida suulises pärimuses kindlalt tõendatud ugalane. Rahvalauludes ja ütlemistes on ugalane sõna, mille keskne tähendus seostub võõraga, muulasega ('sõnakehv, taipamatu inimene, kõnedefektiga inimene, umbkeelne, vaenlane') $)^{5}$. Ajalooline maanimetus Ugaunia, Ugania, Ungania, Ugandi, Oandi (EKNR: Ugandi; Grünthal 1997: 211) seostub üheselt lõunaeesti tuumikalaga, Otepää ümbrusega. Talupoegi, kellel on selline lisanimi, leidus XVII sajandi algul endises Sakalas, nt 1624 Ugalasse Jacob Karksis ja Ukolass Poepe Halliste Kamali külas (Rev 1624 PL: 50, 55). Oletus, et ugalase-sõna aitas *Adsela ümber kujundada *Udsalaks ning et läti keeles nimetusega adzaļi $\sim$ adzeļi kutsutud inimesed olid Lõuna-Eestis tekkinud variatsiooni alusel udsaliq ehk udsalasõ $q$ ehk udsalased, ei mõju siiski väga usaldusväärselt. Nõrgaks kohaks jääb rööpsete $a$-alguliste nimetuste puudumine.

Kui pöörata pilk Läti aladelt kaugemale, siis ka Valgevene põhjanurgas, piirkonnas, mis kuulus I ja II maailmasõja vahel Poolale, sajandeid varem pikka aega Rzeczpospolitale, leidub külanõukogu keskus Удзела (Udziela). Poola keeles nimetati kohta $U d z i a t$, kuid poola perekonnanimi Udziela on samakujuline. Vene keeles on valgevene afrikaadi $d z$ asemel ajalooliselt vanem klusiil $d$ : Удело. Kuna Udsali-nimede Eestis ilmumise aeg on just Poola aeg, siis on siirdnimi Udziela kandist iseendast päris hea seletus nende jaoks.

4 Näiteid soome murrete sõnaraamatust: jatkale 'laiskasta miehestä' jetkale' [hauesta:] vonkale' jotkale 'isokokoisesta, pitkästä (vetelästä, laiskasta): vonkale, vötkäle' jutkale 'isosta, kookkaasta, tanakasta ihmisestä, eläimestä, kappaleesta' jytkäle 'paksusta, tukevasta olennosta' jätkäle 'isokokoisesta: jöntikkä, vonkale' jötkäle 'kookkaasta, pitkulaisesta olennosta, esinestä tms' (Jarva 2003: 81).

5 Vrd Võrumaa rahvalaulude tekste: otsan uutva ugalase, veeren vahtva venelase / otsan orje uttetas, veeren verda valõtas (tekst pärineb Ugandisse kuulunud Kanepi kihelkonnast); Olli orjan, käve karjan / olli orjan Uga rajal (Remmel 2002: 158-159). 


\section{Kokkuvõte}

Udsali ja Adsele on nimed, mille arengus võib läbi aegade märgata paralleele, kuid mille päritolu on tõenäoliselt erinev.

Kohanimed Udsali ja Utsali on varasemad talupoegade lisanimed, mille kohta on Poola-aegsetes dokumentides kasutatud kirjakujusid Uczal, Uczali, Uczely, Vdzela ja Odzal. Erilist tähelepanu äratavad variandid Odzalan ja Oczlan. Viimastes võib kahtlusteta ära tunda lane-liitega lisanime *odsalane $\sim$ udsalane. Arvestades küllalt suurt esinemissagedust ja seda, et lisanimi ilmub sõltumatult viies paikkonnas Eesti lõunapiiri lähedal, on põhjust pidada udsalast etnonüümiks. Lisanime võib siiski võrrelda ka lõunaeesti apellatiiviga $u d s u$ 'udu, ebe, udusulg' ja sellest tuletatud verbiga udsalõma '(udsu kombel) hõljuma'. Teine apellatiivse seose võimalus on karu tähendava läänemeresoome-mordva sõna * okti lõunaeesti vaste *otś : ote(n). Nimesid Utso, Otśu ja miks mitte ka Udsu-nimesid võiks pidada ka sellest sõnast alguse saanuteks. Nii oleks *udsalane ehk hoopis *utslane 'karulane'? Veel üks võimalus Udsali-nimesid seletada on talupoja lisanime seos Valgevene kohanimega Udziela.

Etnonüümi võimaluse korral äratab tähelepanu suur sarnasus Adsele muinasmaakonna nimega. Nime algusvokaali vahetumisele ( $a$ asemel $u$ ) pole siiski piisavalt head seletust. Rõhulise silbi $a$ labialiseerumist ehk muutumist $o$-ks esineb palju läti keele kohalikus malēnieši murdes (samuti nagu latgali keeles). Nii on mõeldav, et maanimetus * Odzala ja etnonüüm *odzaḷi arenesid sellisteks esmalt läti keele poolel. Lõunaeesti keelde laenatuna kujunes *ods-alguline nimi ümber $u d s$-alguliseks. Teine mõeldav tuletuskäik on naabrite kohta käiva etnonüümi ekspressiivne varieerumine, mille puhul $u$ tekkimist võib olla toetanud sarnaselt kõlav ja Lõuna-Eestis hästi tuntud etnonüüm ugalane.

Artiklis pakuti välja ajaloolise kohanime Adsele (*Adsela) täiendatud etümoloogia: nimi sisaldab äärt, serva ja piiri tähendavat läänemeresoome sõna *akja, mis on vana laensõna $(<$ germaani *agjā). Oluline on teada, et esialgu nimetati nii küllalt suurt maa-ala, mille tähtsaim keskus XII sajandil oli Alūksne. Algne territooriumi nimi anti XIII sajandil Koiva jõele rajatud linnusele Adsele (läti Gaujiena, lõunaeesti Koivaliin). Vanimate nimekujude Очела, Agzele ja Adsele analüüsis jõuti seisukohale, et nimeelemendi piir läheb $A g+$ zele, $A d+$ sele vahelt. Nii kuulub see nimi samasse rühma mitme Liivimaa liivlaste sele-lõpulise kohanimega XIII sajandil. Küsimuses, kas -sele (*-sela) sisaldab läänemeresoome 
*selkä sälkä 'selg' nõrga astme genitiivikuju *-sälä või on see kombinatsioon kahest sufiksist (Paul Alvre ettepanek), ei ole kindlat seisukohta võetud. Nii on kohanime mõlemaid struktuure *ad' + sälä ja *ad' $+s e+$ la võimalikuks peetud.

\section{Kirjandus}

Alvre, Paul 1985. Eesti ja liivi keeleaines Henriku Liivimaa kroonikas (III). Kohanimed. - Keel ja Kirjandus 1, 32-36; 2, 96-105.

Ancītis, Krišjān, Aleksandr Jansons 1967. Mõnest Muinas-Läti kohanimest. Etnograafiamuuseumi aastaraamat XXII. Tallinn: Valgus, 302-311.

Balode, Laimute, Ojārs Bušs 2015. No Abavas līdz Zilupei. Vietvārdu cilmes issā vārdnīca. From Abava to Zilupe. The origin of Latvian geographical names. A short dictionary. Zin. red. S. Rapa. Rīga: LVA.

Bauer, Albert 1933. Die Wartgutsteuerliste der Komturei Goldingen. - Mitteilungen aus der livländischen Geschichte 25 (2). Riga: W. F. Häcker, 109-194.

Breidaks, Antons 1997. Ethnolinguistic contacts between Lettgallians and Selonians and Baltic Finns. - Humanities and Social Sciences Latvia 3 (16). Rīga: University of Latvia, 93-113.

EKNR = Marja Kallasmaa, Evar Saar, Peeter Päll, Marje Joalaid, Arvis Kiristaja, Enn Ernits, Mariko Faster, Fred Puss, Tiina Laansalu, Marit Alas, Valdek Pall, Marianne Blomqvist, Marge Kuslap, Anželika Šteingolde, Karl Pajusalu, Urmas Sutrop 2016. Eesti kohanimeraamat. Toim. Peeter Päll, Marja Kallasmaa. Eesti Keele Instituut, Võru Instituut, Eesti Kirjandusmuuseum. Tallinn: Eesti Keele Sihtasutus.

EM IX = Mari Mets, Anu Haak, Triin Iva, Grethe Juhkason, Mervi Kalmus, Miina Norvik, Karl Pajusalu, Pire Teras, Tuuli Tuisk, Lembit Vaba 2014. Lõunaeesti keelesaarte tekstid. Toim. Ellen Niit. (= Eesti murded IX.) Tallinn: Eesti Keele Instituut, Tartu Ülikool.

Grünthal, Riho 1997. Livvistä liiviin. Itämerensuomalaiset etnonyymit. (= Castrenianumin toimitteita 51.) Helsinki.

Hakulinen, Lauri 1979. Suomen kielen rakenne ja kehitys. 4., korjattu ja lisätty painos. Helsinki: Otava.

HLK = Henriku Liivimaa kroonika. Heinrici chronicon Livoniae. 1982. Tlk. Richard Kleis. Toim. Enn Tarvel. Tallinn: Eesti Raamat.

Jarva, Vesa 2003. Venäläisperäisyys ja ekspressiivisyys suomen murteiden sanastossa. (= Jyväskylä studies in humanities 5.) Jyväskylä: Jyväskylän yliopisto. https://jyx.jyu.fi/dspace/bitstream/handle/ 123456789/13423/9513915441.pdf?sequence $=1$. 
Johansen, Paul 1938. Bruchstücke des Landbuches der Ordensmeister für Rujen und Helmet. - Beiträge zur Kunde Estlands. Hrsg. von der Estländischen Literärischen Gesellschaft. 21. Band. Mit 8 doppelseitigen Tafeln auf Kreidepapier und 14 Abbildungen im Text. Tallinn, 43-61.

Kalima, Jalo 1952. Slaavilaisperäinen sanastomme. Tutkimus itämerensuomalaisten kielten slaavilaisista lainasanoista. (= Suomalaisen Kirjallisuuden Seuran toimituksia 243.) Helsinki: Suomalaisen Kirjallisuuden Seura.

Kettunen, Lauri 1955. Etymologische Untersuchung über estnische Ortsnamen. (= Suomalaisen Tiedeakatemian toimituksia B, 90 (1).) Helsinki: Suomalainen Tiedeakatemia.

Leikuma, Lidija 2003. Latgalīšu volūda 1. Intensīvā mācību kursa materiāli. Sanktpēterburgas Valsts universitāte.

LUB I = Liv-, Est- und Kurländisches Urkundenbuch nebst Regesten. Begründet von F. G. Bunge. I-VI, 1853-1910. Hrsg. F. G. Bunge. Riga, Moskau.

Lvv I = Jānis Endzelīns 1956. Latvijas PSR vietvārdi. I, A-J. Latvijas PSR Zinatnu akademija. Valodas un literaturas instituts. Rīgā: Latvijas PSR zinatnu akademijas izdevnieciba.

Oksanen, Auli 2007. Karhu, kontio, ohto ja otso. Karhun nimitysten kielellisillä lähteillä. Etymologinen tutkimus. Pro gradu -tutkielma. Suomalaisugrilainen laitos. Helsingin yliopisto.

PA I = Polnische Akten. I, 1582-1591. 1970. Hrsg. Oleg Roslavlev. (= Hefte zur Landeskunde Estlands 5.) München.

PA II = Polnische Akten. II, 1586-1616. 1973. Hrsg. Oleg Roslavlev. (= Hefte zur Landeskunde Estlands 7.) München.

PA IV = Polnische Akten. IV, 1583-1590. 1973. Hrsg. Oleg Roslavlev. (= Hefte zur Landeskunde Estlands 6.) München.

Pajusalu, Karl, Eberhard Winkler 2011. Salatsi liivi kohanimed keelekontaktide kajastajana. - Keel ja Kirjandus 3, 176-189.

Pall, Valdek 1997. L'em't'ne. Tallinn: Eesti Keele Sihtasutus.

Remmel, Mari-Ann 2002. Viru mees viljapulli, Harju mees aganapulli. Piirkondlike suhete kajastumisest eesti rahvapärimuses. - Mäetagused 21, 141-192.

Rev 1601 = Die Revision Livlands 1601. Estnisches Siedlungsgebiet. 1967. Hrsg. Oleg Roslavlev. (= Hefte zur Landeskunde Estlands 3.) WolfratshausenWaldram.

Rev 1624 PL = Das Pernauer Land 1624. 1967. Hrsg. Oleg Roslavlev. (= Hefte zur Landeskunde Estlands 2.) Wolfratshausen-Waldram.

Rev 1638 = Liivimaa 1638. a maarevisjon. Eesti asustusala. I, Kaguosa. 1941. (= ENSV Riigi Keskarhiivi Tartu osakonna toimetused 1 (7).) Tartu: Teaduslik Kirjandus. 
SLW = Salis-livisches Wörterbuch. 2009. Hrsg. Eberhard Winkler, Karl Pajusalu. (= Linguistica Uralica. Supplementary Series 3.) Tallinn: Teaduste Akadeemia Kirjastus.

SPK $=$ Suomalainen paikannimikirja. 2007. Päätoim. Sirkka Paikkala. (= Kotimaisten kielten tutkimuskeskuksen julkaisuja 146.) Karttakeskus, Kotimaisten kielten tutkimuskeskus.

SSA = Suomen sanojen alkuperä. Etymologinen sanakirja. I-III. 1992-2000. (= Suomalaisen Kirjallisuuden Seuran toimituksia 556. Kotimaisten kielten tutkimuskeskuksen julkaisuja 62.) Helsinki.

Tarvel, Enn 1975. Kas Otšela tšuudid olid Koivalinna eestlased? - Keel ja Kirjandus 9, 549-553.

Valk, Heiki 2009. Hilisrauaaeg (1000/1050-1225). - Setomaa 2. Vanem ajalugu muinasajast kuni 1920. aastani. Tartu: Eesti Rahva Muuseum, 126-189.

Valk, Heiki, Silvia Laul 2014. Siksälä kalme I. Muistis ja ajalugu. Tartu Ülikool. Ajaloo ja arheoloogia instituut. Arheoloogia osakond. Tartu.

VES = Võro-eesti synaraamat. Võru-eesti sõnaraamat. 2002. Kokko pandnuq Jüvä Sullõv. (= Võro Instituudi toimõndusõq 12.) Tarto-Võro.

\section{Arhiivimaterjalid}

EAA $=$ Rahvusarhiiv. Eesti ajaloo arhiiv. 


\title{
Udsali and Adsele
}

\author{
EVAR SAAR
}

The article examines the South Estonian place name cluster Udsali $\sim$ Utsali. This name was used as a peasant surname in the 16th-17th centuries more extensively than in modern-day place names. Attention is also drawn to some mentions from the 16 th century which contain the ethnonym-like surname $*$ Udsalane. While in Eesti kohanimeraamat (2016) I conjectured that Udsali is a High German or Jewish loan name, I now believe that the name either comes directly from South Estonian or is a borrowing of nearby southern origin. This surname came into use in the 16th-17th centuries independently in five places near Estonia's southern border.

The old surname Udsali has been compared to the word $u d s u$ 'fog, fluff, plumule' and the verb udsalõma 'to hover like fog or dust'. The comparable South Estonian place names $U d s u \sim U t s u$, which also appear as family names and have previously been used as peasant surnames, are also indigenous. The oldest written mention of $U d s u$ dates back to the 15th century. The meaning 'fog, fluff, plumule' could be the basis for the peasant surname, but this is not very likely. Another potential source of the name is the Finnic-Mordvin word for 'bear', the Uralic reconstruction of which is *okti. The regular South Estonian equivalent *otś and the genitive form *ote $(n)$ are represented in the word ott, denoting a bear, and the place name Otepää. The place names Otśu, Utso and Udsu could be regarded as having originated from this word. Thus the ethnonym-like surname *udsalane could actually be *utslane 'bear man'? Another possible explanation for the Udsali name cluster is the connection between the peasant surname and the Belorussian place name Udziela.

Presuming that the basis for the surname Udsali $\sim$ Udsalane is an ethnonym no longer in use, one candidate is the, the ancient county Agzele $\sim$ Adsele on the territory of modern-day Latvia, to the south of Southeastern Estonia. The presumed earliest mention of this county comes from the Pskov chronicle from the year 1111: на Очелу (< Очела). In 12th-century Russian chronicles, the inhabitants of Očela are given as Chudes (i.e. Finns). In Old Russian orthography, the short Finnic $a$ was always rendered as $o$. However, there is no adequate explanation for the change that actually took place in the initial vowel of the name $(a>u$ or $a>o>u$ ). The labialization, i.e. change to $o$, of stressed $a$ appears quite often in 
the local Latvian Malēnieši dialect (as well as in Latgalian). Thus it is plausible that the county name *Odzala and the ethnonym *odzali first developed as such in the Latvian-language environment. Borrowed into South Estonian, the initial * ods was adapted to $u d s$. Another possible derivation path is via expressive variation of the ethnonym denoting the neighboring people, wherein the emergence of $u$ could have been supported by the similar-sounding ethnonym ugalane, well known in South Estonia. However, as both of these explanations are somewhat artificial, Udsali and Adsele should be regarded as names that cannot be linked to one another, at least not on the basis of currently existing knowledge.

The article presents an improved etymology for the historical place name Adsele (*Adsela) - the name includes the Finnic word *akja 'edge, brink, border' an old borrowing from Germanic *agjā. This explanation was first given by Krišjān Ancitis and Aleksandr Jansons in 1967, but their article has remained relatively unknown. It is important to note that this name was initially used for quite a large area, the most important center of which in the 12th century was Alūksne. The original name for the region was later given to the castle built along the Gauja River, called Adsele in German (Latvian Gaujiena, South Estonian Koivaliin). The analysis of the oldest name forms Очела, Agzele and Adsele concludes that the border of the name element goes between $\mathrm{Ag}+\mathrm{zele}, \mathrm{Ad}+$ sele. Thus this name belongs in the same group with a number of other 13th-century Livonian place names ending in -sele: Sattesele, Cubbesele, Vitisele etc. The article does not take a stance on whether the ending -sele (*-sela) contains the weak grade genitive form *-sälä of the Finnic word *selkä sälkä 'back' or whether it is a combination of two suffixes (as Paul Alvre has suggested). Therefore, the structures *ad'+sälä and ${ }^{*} \mathrm{ad}^{\prime}+\mathrm{se}+\mathrm{la}$ are both considered possible.

Keywords: onomastics, surnames, ethnonyms, place names, etymology, South Estonian, Latvian

\author{
Evar Saar \\ teadus- ja arendusosakond \\ Võru instituut \\ Tartu 48 \\ 65609 Võru \\ saareevar@gmail.com
}

